\title{
Effects of Cholinergic Drugs on Aversive Operant Behavior Induced by Dorsal Central Gray Stimulation in Rats
}

\author{
Minehiro MORIYAMA, Yasuyuki ICHIMARU, Yutaka GOMITA* \\ and Tamotsu FUKUDA* \\ Department of Pharmacology. Daiichi College of Pharmaceutical Sciences, \\ 22-1 Tamagawa-cho, Minami-ku, Fukuoka 815, Japan \\ *Department of Hospital Pharmacy, Okayama University Medical School. \\ 2-5-1 Shikata-cho, Okayama 700. Japan
}

Accepted July 29.1985

\begin{abstract}
Involvement of a central cholinergic mechanism in the central aversive operant behavior induced by dorsal central gray (DCG) stimulation was investigated in rats. Each animal was chronically implanted with bipolar electrodes at the DCG and was trained to press a lever to decrease the DCG-stimulation current. Physostigmine $(0.1$ and $0.2 \mathrm{mg} / \mathrm{kg}$. i.p.) and arecholine $(0.5-2.0 \mathrm{mg} / \mathrm{kg}$. i.p.) produced an increase of DCG-stimulation threshold at $0.5-2 \mathrm{hr}$ and $1-4 \mathrm{hr}$. respectively, after the administration. On the other hand, scopolamine $(0.1-0.5 \mathrm{mg} /$ $\mathrm{kg}$, i.p.) and atropine ( 5 and $10 \mathrm{mg} / \mathrm{kg}$, i.p.) caused a marked decrease of the threshold at $0.5-2 \mathrm{hr}$ after. In addition, an increasing effect of physostigmine on the threshold was decreased by scopolamine. Physostigmine potentiated the increasing effect of chlorimipramine on the stimulation threshold, while scopolamine suppressed it. These results suggest that the operant behavior induced by DCG. stimulation may be related to not only the central serotonergic mechanism but also to the cholinergic mechanism.
\end{abstract}

A number of investigators have shown that the electrical stimulation of the mesencephalon or periventricular system produces aversive operant behavior and/or fear responses in rats, cats and mice $(1-6)$. It is known that the stimulation applied to the dorsal part of the central gray (DCG) has strong aversive characteristics and also caused the increase of arterial blood pressure. heart rate and respiration in the rat (7). Further, Kiser et al. (8) showed that DCG stimulation induced aversion in rats was apparently affected by the manipulation of brain serotonin (5-HT) function, by using the decremental lever pressing (DLP) paradigm to decrease DCG-stimulation current. Recently, Cazala and Garrigues (6) also reported that 5-methoxy-N,N-dimethyltryptamine decreased the latency time of the escape response induced by central gray stimulation in mice. in addition, in the previous study, the authors have observed that the
DCG-stimulation threshold was increased by 5-hydroxytryptophan (5-HTP) and chlorimipramine, and it was decreased by $p$ chlorophenylalanine (PCPA) and cyproheptadine (9).

On the other hand, there are many reports showing that a cholinergic mechanism is involved in various behaviors maintained by peripheral aversion such as foot shock. For instance, it have been reported that scopolamine facilitates the avoidance response (1013), and inhibits aggressive behavior induced by foot shock $(14,15)$ and behavioral suppression performed by combining foot shock aversion with food reward (16). However, it is uncertain whether a central cholinergic mechanism is involved in aversive operant behavior induced by the central DCG-stimulation. Therefore, the purpose of the present study was to examine the effect of cholinergic drugs and combination effect with chlorimipramine, a 5-HT uptake 
inhibitor, on escape operant behavior induced by the DCG-stimulation by means of DLP paradigm technique (5).

\section{Materials and Methods}

Subjects: Eighteen male Wistar rats weighing $250-300 \mathrm{~g}$ at the time of electrode implantation were used as subjects. They were housed one or two in plastic cages $(26 \times 36 \times 25 \mathrm{~cm})$ and were given food and water ad libitum throughout the experiment. All the animals were maintained on a $12 \mathrm{hr}$ light-dark cycle (light on 0900 to 2100 ) and at a room temperature of $22-24^{\circ} \mathrm{C}$ with a relative humidity of $50-60 \%$.

Surgery and histology: All animals were anesthetized with $\mathrm{Na}$ pentobarbital $45 \mathrm{mg} /$ $\mathrm{kg}$, i.p., and were placed on a stereotaxic instrument (Takahashi). Each animal was chronically implanted with a bipolar stainless steel electrode $(250 \mu \mathrm{m}$ in diameter, insulated except at the tip) in the DCG (A: 0.6, L: 0.6, $\mathrm{H}: 0.4 \mathrm{~mm}$ ) according to the stereotaxic coordinates of König and Klippel's atlas (17). The electrodes were bilaterally inserted into the target sites at a $15^{\circ}$ angle in order to avoid piercing the sagittal venous sinus as much as possible. All animals were given 150,000 units of penicillin subcutaneously after ihe surgery.

At the end of the experiment, animals were given an overdose of $\mathrm{Na}$ pentobarbital. and the head was perfused with $0.9 \%$ saline and then $10 \%$ formalin through the heart. The brain was immersed in the formalinsaline solution at least one week. After taking the skull off, each brain was put on the platform in a cryostat (Chiyoda) and cut in $40 \mu \mathrm{m}$ sections, followed by staining with cresylviolet. The location of implanted electrode tips in the DCG was verified by the inspection of stained sections.

Apparatus: The experiment was carried out in a Skinner box $(30 \times 27 \times 25 \mathrm{~cm})$ which was constructed of transparent Plexiglass. The floor consisted of a stainless steel grid. with bars of $5 \mathrm{~mm}$ diameter that were spaced $1.0 \mathrm{~cm}$ apart to allow urine and feces to fall to the tray. The metal lever in the Skinner box was placed $4.5 \mathrm{~cm}$ above the grid floor and protruded $2.5 \mathrm{~cm}$ into the box. A lever press resulted in turn off or decrease of the brain stimulation current. A swivel was mounted in the ceiling of the chamber holding the electrode lead. which allowed the animal to move freely. The stimulation of DCG was derived from a square-wave stimulator (Watanabe), which was able to give a decremental schedule of brain-stimulation current.

Procedure: After at least one week of recovery period from implantation surgery, each animal was placed into the Skinner box. and the stimulating cable was connected to the electrode plug mounted in the animal's head. The DCG was stimulated with a negative square-wave. The stimulation conditions were 5 trains/sec. $100 \mathrm{msec}$ train duration and 0.5 msec pulse duration, with current in the range of $100-600 / \mathrm{A}$. The stimulation current was gradually increased until the subject began to show aversive behaviors such as rapid running around the box and jumping, defecation and urination. These rats were trained to press a lever to stop the DCG-stimulation (escape response) and learned the escape response within one or two days. Only animals that showed the escape response were trained with the DLP paradigm in which the rat itself could decrease the DCG-stimulation by pressing a lever.

In the DLP paradigm, one trial consisted of a $120 \mathrm{sec}$ stimulation period alternating with a $60 \mathrm{sec}$ rest period. During the stimulation period, each lever press reduced DCGstimulation current by $5 \%$ of the initial current. An initial stimulation current was chosen such that the daily average lever pressing rate was 4-6 per trial. The threshold of DCGstimulation current was determined as the stimulation-current at which the rat could no longer press the lever during the stimulation period. After the stimulation-threshold was stable for three successive days, the animals were treated with the drugs. The drug test was performed using 10 trials at $0.5,1,2,4$ and $24 \mathrm{hr}$ postinjection. The animals were allowed to rest for at least 7 days between drug administrations.

Drugs: Drugs used in this experiment were scopolamine hydrobromide (Sigma). atropine sulfate (Merck), physostigmine salicylate (Merck), arecholine hydrobromide (Sigma) and chlorimipramine (Ciba Geigy). 
All drugs were dissolved in saline and administered i.p. Control animals were given saline at $0.1 \mathrm{ml}$ per $100 \mathrm{~g}$ body weight.

Statistical analysis: The experimental data were presented as the mean percent change of the stimulation-threshold and analyzed statistically by the Mann-Whitney $U$-test (18).

\section{Results}

Histology: Figure 1 illustrates the electrode tip placement in the DCG. All electrode tips for aversive brain stimulation were located in or on the border of the DCG.

Effects of cholinergic drugs: Figures 2 and 3 show effects of physostigmine and arecholine at various doses on a DCGstimulation threshold. As shown in Fig. 2. physostigmine at doses of 0.1 and $0.2 \mathrm{mg} /$ $\mathrm{kg}$ caused an increase of DCG-stimulation threshold at $0.5-4 \mathrm{hr}$ after the administration in comparison with the vehicle group. Peak time of this drug effect at these doses was $0.5-1 \mathrm{hr}$ after the administration. In this case. significant differences were found at $0.5,1$. 2 and $4 \mathrm{hr}(U=0 . P<0.01$, respectively $)$ after administration of $0.1 \mathrm{mg} / \mathrm{kg}$ physostigmine, and at 0.5 .1 and $2 \mathrm{hr}(U=0 . P<0.01$, respec tively) after a dose of $0.2 \mathrm{mg} / \mathrm{kg}$. As shown in Fig. 3, arecholine at doses of 0.5, 1.0 and $2.0 \mathrm{mg} / \mathrm{kg}$ produced an increase of stimu- lation-threshold at 1-4 hr after the drug administration in comparision with the vehicle administered group. In this case. significant differences were found at 1 $(U=2.5, P<0.05), 2(U=4.5, P<0.05)$ and $4 \mathrm{hr}(U=0 . P<0.01)$ after $0.5 \mathrm{mg} / \mathrm{kg}$ administration, at 1,2 and $4 \mathrm{hr}(U=0, P<0.01$. respectively) after $1.0 \mathrm{mg} / \mathrm{kg}$ administration, and at $1(U=2, P<0.05), 2(U=3$, $P<0.05)$ and $4 \mathrm{hr}(U=0, P<0.01)$ after 2.0 $\mathrm{mg} / \mathrm{kg}$ administration. The slight increase of spontaneous activity in a Skinner box at $0.5 \mathrm{hr}$ after the administration of $2 \mathrm{mg} / \mathrm{kg}$ arecholine was observed (data not shown).

The effects of scopolamine and atropine are shown in Figs. 4 and 5 . As shown in Fig. 4, scopolamine at doses of $0.1-0.5 \mathrm{mg} /$ $\mathrm{kg}$ produced a dose-dependent decrease of stimulation-threshold. Peak time of this drug effect at these doses was $0.5 \mathrm{hr}$ after the administration. Significant differences were found at $0.5 \quad(U=0, P<0.01), 1 \quad(U=3.5$, $P<0.05)$ and $2 \mathrm{hr}(U=2, P<0.05)$ after 0.2 $\mathrm{mg} / \mathrm{kg}$ administration and at $0.5 \quad(U=0$. $P<0.01), 1$ and 2 hr $(U=2.5$ and $4 . P<0.05$. respectively) after $0.5 \mathrm{mg} / \mathrm{kg}$ administration in comparison with the vehicle group. As shown in Fig. 5. atropine at doses of 5 and $10 \mathrm{mg} / \mathrm{kg}$ also caused a significant decrease of stimulation threshold after the administration, as well as in the case of scopolamine.

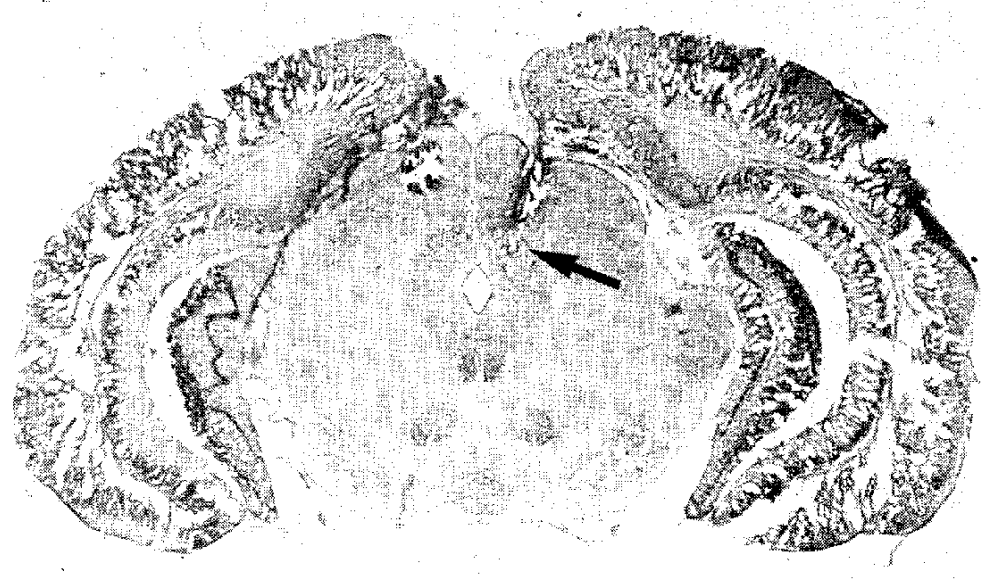

Fig. 1. Nissl-stained coronal section showing the tip of the electrode at the dorsal central gray (DCG) for aversive brain stimulation. 


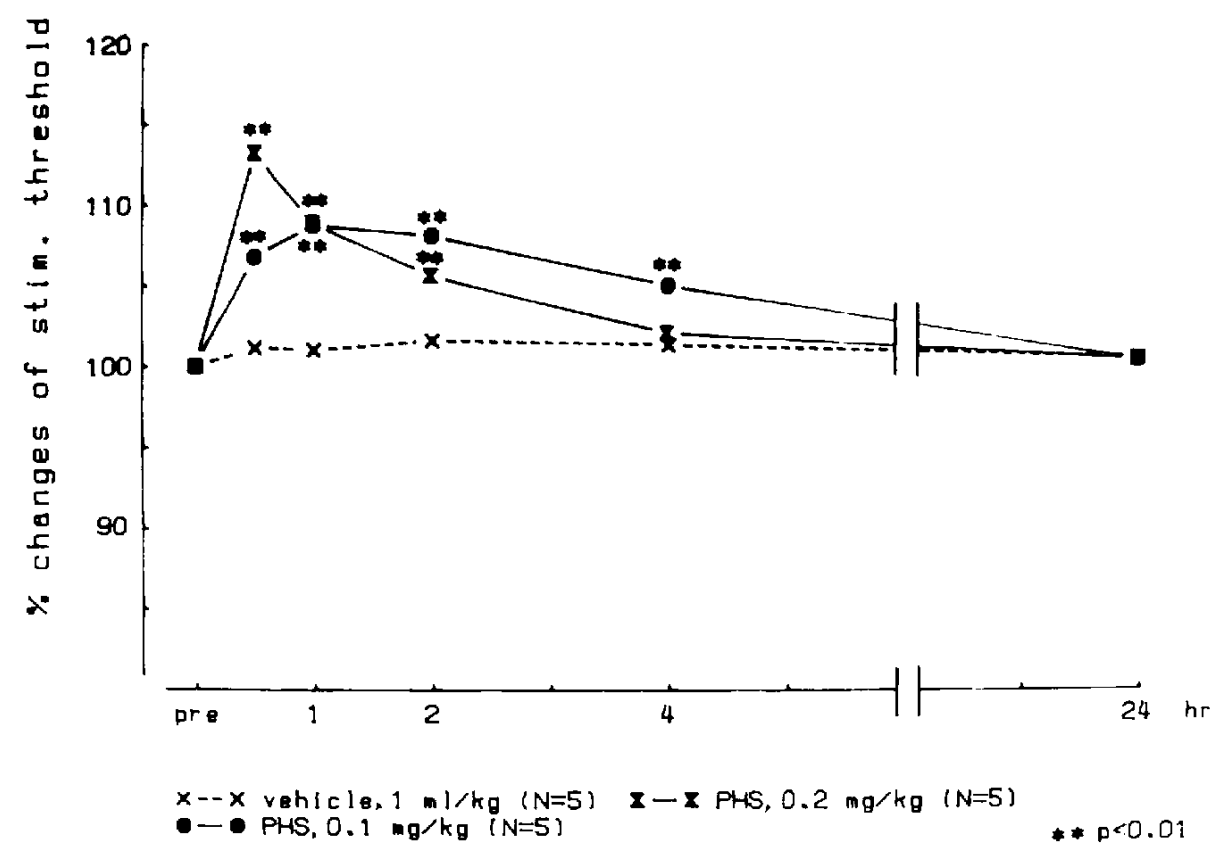

Fig. 2. Effects of physostigmine on DCG-stimulation threshold in rats. Each point represents the mean percent changes of threshold from the pre-injection value. Asterisks indicate significant differences from the saline control. PHS: physostigmine.

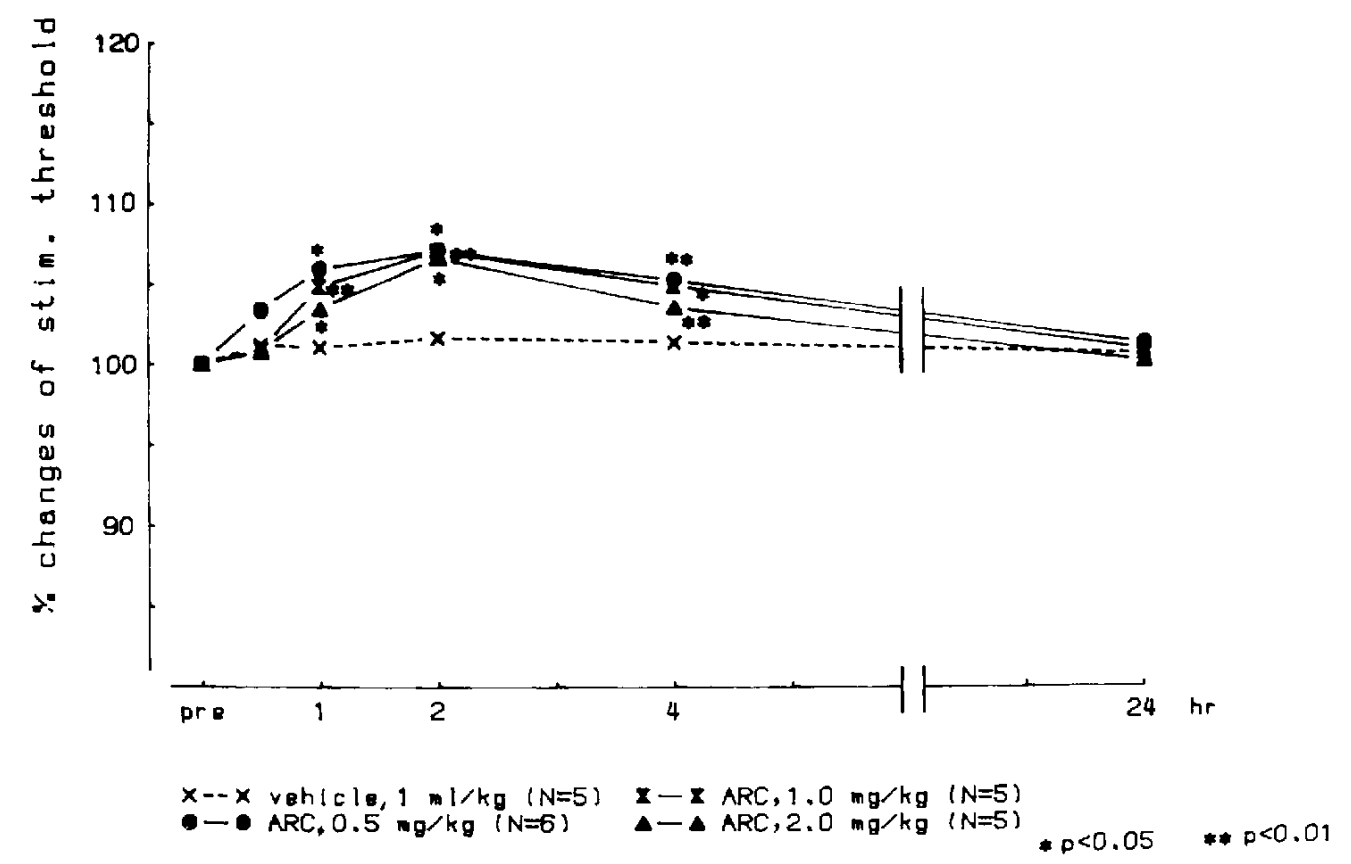

Fig. 3. Effect of arecholine on DCG-stimulation threshold in rats. Each point represents the mean percent changes of threshold from the pre-injection value. Asterisks indicate significant differences from the saline control. ARC: arecholine. 


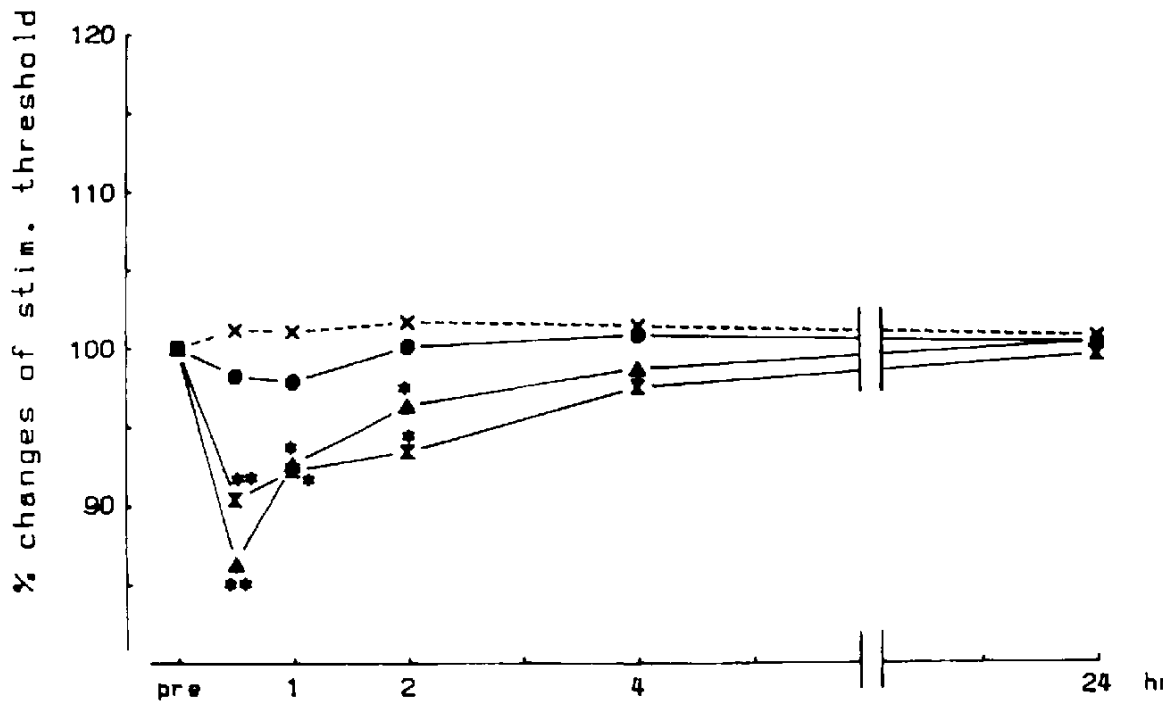

\section{$x--x$ rohicle, $1-1 / k g(N=5) \quad z-z \operatorname{sCO}, 0.2$ gorkg (N=5)

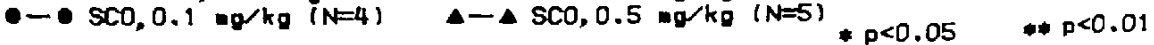

Fig. 4. Effect of scopolamine on DCG-stimulation threshold in rats. Each point represents the mean percent changes of threshold from the pre-injection value. Asterisks indicate significant differences from the saline control. SCO: scopolamine.

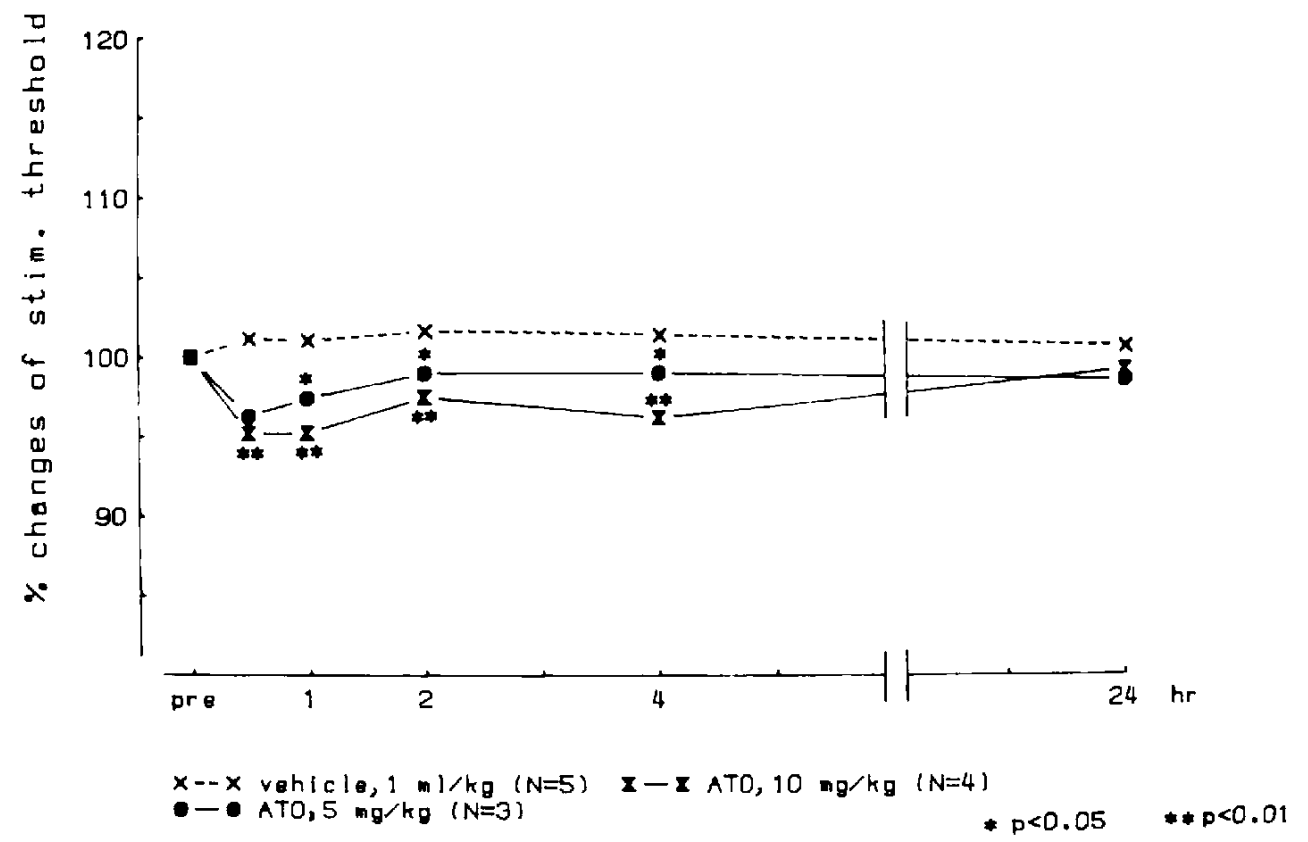

Fig. 5. Effect of atropine on DCG-stimulation threshold in rats. Each point represents the mean percent changes of threshold from the pre-injection value. Asterisks indicate significant differences from the saline contro!. ATO: atropine. 


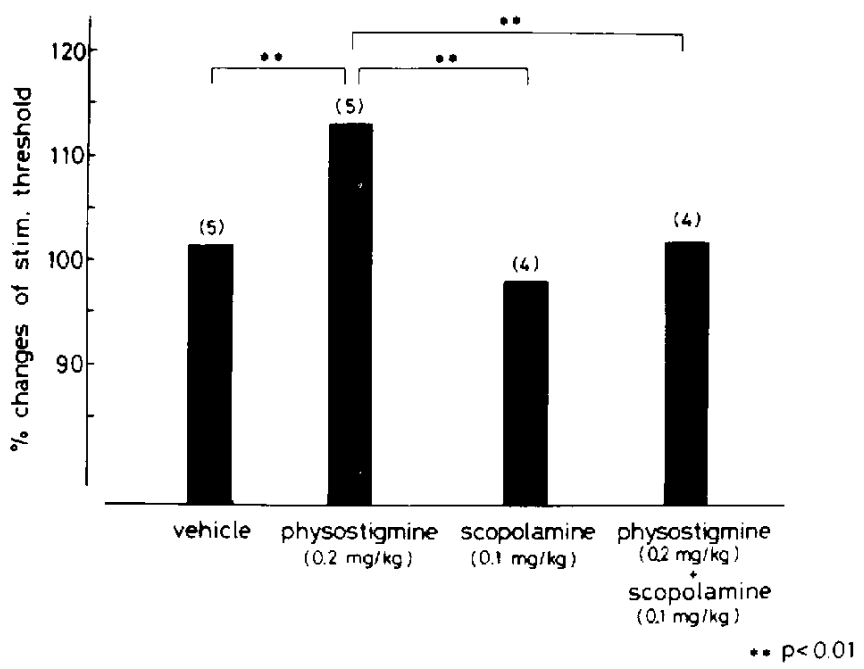

Fig. 6. Combination effect of physostigmine and scopolamine on DCG-stimulation threshold. The measurement in each group was carried out at 0.5 hr after the administration. Each column represents the mean percent changes of threshold from the pre-injection value. Numeral in parenthesis indicate the number of anima!s.

Peak time of this drug effect at these doses was $0.5 \mathrm{hr}$ after the administration. Significant differences were found at $1(U=0, P<0.05)$. $2(\mathrm{U}=0.5, P<0.05)$ and $4 \mathrm{hr}(\mathrm{U}=0, P<0.05)$ after $5 \mathrm{mg} / \mathrm{kg}$ administration and at $0.5,1,2$. 4 hr $(U=0 . P<0.01$, respectively $)$ after 10 $\mathrm{mg} / \mathrm{kg}$ administration. The slight increase of spontaneous activity in the box was observed at $0.5 \mathrm{hr}$ after administration of $0.5 \mathrm{mg} / \mathrm{kg}$ scopolamine or $10 \mathrm{mg} / \mathrm{kg}$ atropine (data not shown).

Combination effect of physostigmine with scopolamine: The combination effect of physostigmine with scopolamine on the stimulation threshold is shown in Fig. 6. This measurement was carried out at the peak time of scopolamine and physostigmine (i.e., $0.5 \mathrm{hr}$ after the administration of these drugs). DCG-stimulation threshold was increased by physostigmine at a dose of 0.2 $\mathrm{mg} / \mathrm{kg}$, but slightly decreased by scopolamine at a dose of $0.1 \mathrm{mg} / \mathrm{kg}$. However, the marked increase of threshold elicited by physostigmine was completely suppressed by combining it with scopolamine. Significant differences were found between the vehicle group and physostigmine group $(U=0, P<0.01)$, the physostigmine group and scopolamine group $(U=0 . P<0.01)$, and the physostigmine plus scopolamine group and physostigmine group $(U=0, P<0.01)$, as shown in Fig. 6 .

Combination effect of cholinergic drugs with chlorimipramine: Figure 7 shows the effect of chlorimipramine alone and the combination effect of $0.1 \mathrm{mg} / \mathrm{kg}$ physostigmine or $0.1 \mathrm{mg} / \mathrm{kg}$ scopolamine with chlorimipramine. The threshold of DCGstimulation on escape response was increased by the administration of chlorimipramine at a dose of $5 \mathrm{mg} / \mathrm{kg}$. This increasing effect by chlorimipramine on DCG-stimulation threshold was potentiated by physostigmine at a dose of $0.1 \mathrm{mg} / \mathrm{kg}$ and suppressed by scopolamine at a dose of $0.1 \mathrm{mg} / \mathrm{kg}$. There were significant differences between the vehicle group and chlorimipramine group or chlorimipramine plus physostigmine group $(U=0, P<0.01$ respectively), chlorimipramine group and chlorimipramine plus scopolamine group $(U=0, P<0.05)$, and chlorimipramine plus physostigmine group and chlorimipramine plus scopolamine group $(U=0$. $P<0.05)$, as shown in Fig. 7 .

\section{Discussion}

Several reports have suggested that mesencephalic DCG plays an important role in the integration of aversive behavior in the 


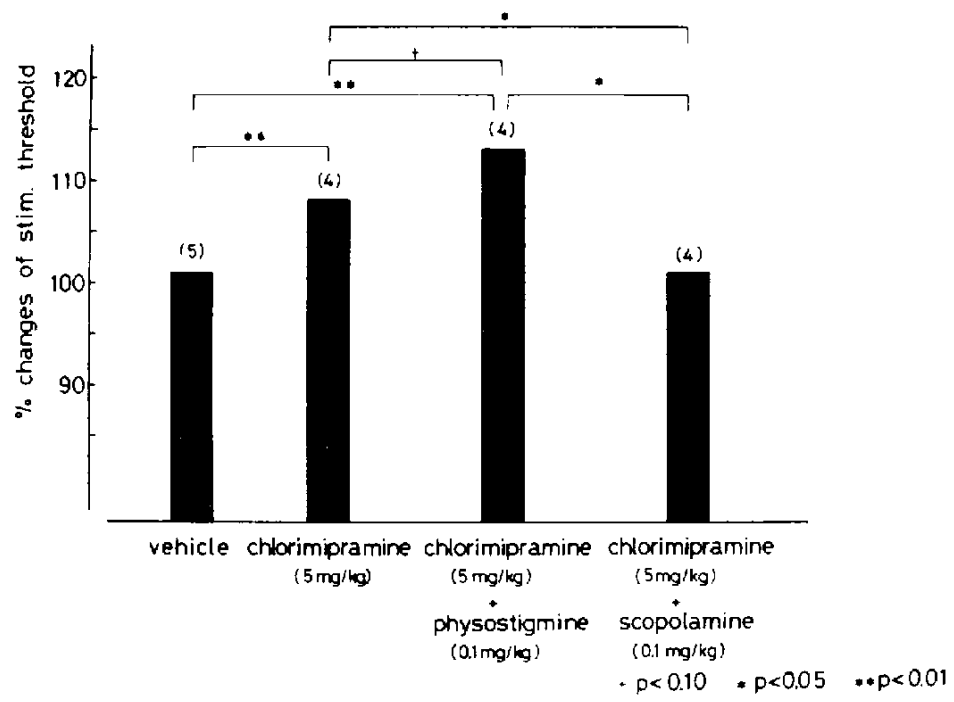

Fig. 7. Effects of cholinergic drugs on chlorimipramine increasing effect on DCG-stimulation threshold. The measurement in each group was carried out at $2 \mathrm{hr}$ after chlorimipramine administration. Cholinergic drugs were injccted at $1.5 \mathrm{hr}$ after chlorimipramine administration. Each column represents the mean percent changes of threshold from the pre-injection value. Numeral in parenthesis indicate the number of animals.

rat (1-6). In the present study, the DCGstimulation induced aversive behaviors such as running. jumping and escape response, and the stable stimulation-threshold on escape response was maintained in the $D\llcorner P$ paradigm. The present data which examined the effect of cholinergic drugs on this threshold show that the escape response induced by brain stimulation is affected by cholinergic drugs. That is, low doses of physostigmine and arecholine increased the DCG-stimulation threshold, whereas low doses of scopolamine and atropine decreased the threshold.

With regard to the escape behavior induced by foot shock. Feigley et al. (19) reported that $1 \mathrm{mg} / \mathrm{kg}$ scopolamine. i.p., produced a significant shortening of the escape latency in the rat. Houser and Van Hart (20) also reported that pilocarpine and physostigmine produced an increase of the threshold, while scopolamine and atropine had no effect on the escape response induced by foot shock in the rat. These indicate the possibility that central cholinergic mechanisms may mediate the aversive qualities of foot shock in the rat.
On the other hand, in regard to the escape response induced by DCG-stimulation. Wada and Matsuda (21) have reported that both atropine (antagonist) and physostigmine (agonist) produced a prolongation of the escape latency in the cat, these supporting that a central cholinergic mechanism is not directly involved in the elaboration of the escape performance. In our present data. physostigmine at 0.1 and $0.2 \mathrm{mg} / \mathrm{kg}$ decreased the DCG-stimulation threshold without affecting the spontaneous activity. Arecholine at 0.5 and $1 \mathrm{mg} / \mathrm{kg}$ also showed a decreasing effect without affecting the spontarieous activity. In contrast, scopolamine at doses of 0.1 and $0.2 \mathrm{mg} / \mathrm{kg}$ and atropine at a dose of $5 \mathrm{mg} / \mathrm{kg}$ increased the stimulation threshold without affecting the spontaneous activity. Additionally. it was found that the effect of physostigmine was also antagonized by scopolamine. These data suggest that these doses of cholinergic drugs which do not affect the motor activity show centrally specific effects on the DCG-stimulation induced escape behavior. However, this suggestion is not in agreement with Wada's report (21). The main differences between 
our experiment and their experiment were the paradigms of escape response and the dosage of atropine: we used the DLP paradigm in which the animal itself determined the threshold of DCG-stimulation, and we employed a higher dosage of atropine. Additionally, the stimulation site may be different because we did not observe the defensive behavior that they reported. Hence, this discrepancy may be due to differences in experimental conditions. Thus, these suggest that a central cholinergic mechanism may be involved in the escape behavior induced by DCG-stimulation.

In addition, we examined the interaction between cholinergic and serotonergic mechanisms on the behavior induced by the DCGstimulation. Chlorimipramine at a dose of $5 \mathrm{mg} / \mathrm{kg}$ depressed the escape response induced by DCG-stimulation. This result was consisted with Kiser's report (8) showing that chlorimipramine inhibits the escape response, supporting the hypothesis that $5-H T$ reduces the aversion due to DCGstimulation. The effect of chorimipramine was antagonized by scopolamine and potentiated by physostigmine in the present experiment. This indicates that a central cholinergic neuron may also be a part of the important link in the chain of neurons that maintains the escape behavior induced by DCGstimulation.

In conclusion, these results suggest that the aversive behavior induced by DCGstimulation may be related to not only to a central serotonergic mechanism but also to a central cholinergic mechanism.

Acknowledgement: This research was supported in part by Grant-in-Aid (No. 57770193 to MM and No. 58570110 to $Y G$ ) for Scientific Research from the Ministry of Education, Science and Culture of Japan.

\section{References}

1 Hunsperger, R.W.: Role of substantia grisea centralis mesencephali in electrically-induced rage reaction. In Progress in Neurobiology, Edited by Ariens-Kapper. J.. p. 289-292. Elservier, Amsterdam (1956)

2 Olds, M.E. and Olds, J.: Approach-avoidance analysis of rat diencephaion. J. Comp. Neurol. 120. 259-283 (1963)
3 Valenstein, E.S.: Independence of approach and escape reaction to electrical stimulation of the brain. J. Comp. Physial. Psychol. 60, 20-30 (1965)

4 Routtenberg, A.: Hippocampal activity and brainstem reward-aversion loci. J. Comp. Physiol. Psychol. 72, 161-170 (1970)

5 Kiser, R.S. and Lebovitz, R.M.: Monoaminergic mechanisms in aversive brain stimulation. Physiol. Behav. 15, 47-53 (1975)

6 Cazala, P. and Garrigues, A.M.: Differential aversive effect of mesencephalic central gray stimulation in the mouse. Physiol. Behav. 25, $357-361$ (1980)

7 Schenberg, L.C., de Aguiar, J.C., Salgado, H.C. and Graeff, F.G.: Depressant action of chlorizaepoxide on cardiovascular and respiratory changes induced by aversive electrical stimulation of the brain. Braz. J. Med. Biol. Res. 14, 69-72 (1981)

8 Kiser, R.S., German, D.C. and Lebovitz. R.M. Serotonergic reduction of dorsal central gray area stimulation-produced aversion. Pharmacol. Biochem. Behav. 9, 27-31 (1978)

9 Moriyama, M., Ichimaru, $Y$. and Gomita, $Y$. Effects of serotonergic drugs on operant behavior with intracranial aversive stimulation in rats. Japan. J. Pharmacol. 32, Supp. 254P (1982)

10 Goldberg, M.E., Johnsan, H.E. and Knaak, J.B.: Inhibition of discrete avoidance behavior by three anticholinesterase agents. Psychopharmacologia 7. 72-76 (1965)

11 Leaf, R.C. and Muller, S.A.: Effects of scopolamine on operant avoidance acquisition and retention. Psychopharmacologia 9, 101-109 (1966)

12 Hamilton, L.W. and Grossman, S.P.: Behavioral changes following disuption of centra cholinergic pathway. J. Comp. Physiol. Psychol. 69, 76-82 (1969)

13 Bignami, G. and Rosic, N: Acquisition and performance effects of scopolamine and of treatment withdrawal in avoidance situation. Physiol. Behav, 8, 1127-1134 (1972)

14 Powell, D.A., Milligan, W.L. and Walters, K.: The effect of muscarinic cholinergic blockade upon shock elicited aggression. Pharmacol. Biochem. Behav. 1, 303-314 (1967)

15 Rodgers, R.J. and Brown. K.: The inhibition of shock-induced attack in rat by scopolamine. I.R.C.S. Med. Sci. 1, 73-75 (1973)

16 Margules, D.L. and Stein, L.: Neuroleptic vs tranquilizers: evidence from animals studies of mode and site of action. In Neuro-Psychopharmacology, Edited by Brill, H., Cole, J.O. Deniker, P. and Bradly, P.B., p. 108-120, 
Excerpta Medica Foundation. Amsterdam (1967)

17 König, J.F. and Klippel, R.A.: The Rat Brain. A Stereotaxic Atlas of the Forebrain and LoW Parts of the Brain Stem. Williams and Wilkins. Baltimore (1963)

18 Siegel, S.: Nonparametric Statistics for the Behavioral Sciences. McGraw Hill Inc. New York (1956)

19 Feigley, D.A., Beakey, W. and Saynisch, M.J.: Effect of scopolamine on the reactivity of the albino rat to footshock. Pharmacol. Biochem. Behav. 4, 255-258 (1976)

20 Houser, V.P. and Van Hart, D.A.: Modulation of cholinergic activity and the aversive threshoid in the rat. Pharmacol. Biochom. Behav. 2, 631637 (1974)

21 Wada, J.A. and Matsuda, M.: Learned escape behavior induced by brain electrical stimulation and various neuroactive agents. Exp. Neurol. 32, 357-365 (1971) 